\title{
Photonic Jets for Micro-Etching
}

\author{
Andri Abdurrochman ${ }^{1,2, a}$, Sylvain Lecler ${ }^{2}$, Frédéric Mermet $^{2}$, Joël Fontaine ${ }^{2}$, and Bernard Tumbelaka ${ }^{1}$ \\ ${ }^{1}$ Department of Physics, Faculty of Mathematics and Natural Sciences, Universitas Padjadjaran, J1.Raya \\ Bandung-Sumedang KM 21 Jatinangor, Sumedang 45363, Indonesia \\ ${ }^{2}$ ICube - IPP, Université de Strasbourg, Pôle API, 300 Boulevard Sébastien Brant, BP 10413, 67412 \\ Illkirch, Strasbourg, France \\ ${ }^{3}$ Irépa Laser, Pôle API, Boulevard Sébastien Brant, 67412 Illkirch, Strasbourg, France \\ ${ }^{4}$ ICube - IPP, INSA de Strasbourg, Boulevard de la victoire, 67000 Strasbourg, France \\ ${ }^{a}$ Corresponding author: a.andri@phys.unpad.ac.id
}

\begin{abstract}
Photonic jet is a localized sub-wavelength beam generated at the shadow-side surfaces of microscale dielectric cylinders or spheres, when they are illuminated by an electromagnetic wave. We demonstrate the potential of the photonic jets for micro-etching using a nanosecond Near-IR laser $(\lambda=1064 \mathrm{~nm})$ that has a typical spatial resolution around $70 \mu \mathrm{m}$, limited by its optical focusing head. Combining this laser with micro-scale glass $\left(n_{\mathrm{s}}=1.5\right)$ and $\mathrm{BaTiO}_{3}$ spheres $\left(n_{\mathrm{s}}=\right.$ 1.9) to achieve photonic jets, we can etch two substrates: silicon wafers, which have a significant absorption at $1064 \mathrm{~nm}$, and glass plates, which have a lower absorption at this wavelength. The smallest marks achieved on silicon have an average diameter of $1.3 \mu \mathrm{m}$ which is 50 times smaller than without spheres. Despite the low absorption, micrometric etchings have also been achieved on glass.
\end{abstract}

Keywords- Photonic jets, micro-etching, microsphere, silicon, power laser.

\section{INTRODUCTION}

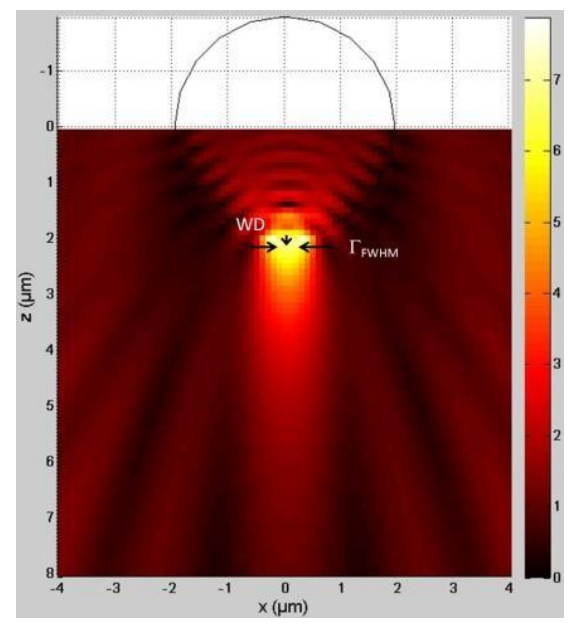

Figure 1.Total electric field norm in the vicinity of a glass sphere $\left(n_{\mathrm{s}}=1.5 ; D_{\mathrm{s}}=4 \mu \mathrm{m}\right)$ is generated by a unitary plane wave $\lambda_{0}=1 \mu \mathrm{m}$ in free space.

The engineering of photonic nanojets, their properties and potential applications, have been studied by many authors during the last ten years [1-28]. Sometime, the phenomenon is referred as photonic jets. Photonic jet is a high concentrated, non-evanescent light beam that can propagate over a range several times longer than the incidence wavelength $\lambda_{\mathrm{o}}$ after emerging in the vicinity of dielectric micro-cylinder or microsphere having a diameter larger than $\lambda_{\mathrm{o}}$. Figure 1 shows the photonic jets computed using the Mie theory and that emerges from a glass microsphere (refractive index $n_{\mathrm{s}}=1.5$; Diameter $D_{\mathrm{s}}=4 \mu \mathrm{m}$ ) illuminated by a unitary plane incidence wave of $\lambda=1 \mu \mathrm{m}$ in free space. It shows a maximum electrical field $E_{\max }=$ $7.8 E_{\mathrm{o}}$ corresponding to a maximum intensity $I=\left(E_{\max }\right)^{2}=$ $61 I_{\mathrm{o}}$ at a distance $W D=0.14 \mu \mathrm{m}$ from the microsphere surface. The photonic jets beam has a width $\Gamma_{\mathrm{FWHM}}=1 \mu \mathrm{m}$ and a length $\zeta_{\text {FWHM }}=3.5 \mu \mathrm{m}$ where the FWHM is smaller than the wavelength.

This paper studies the photonic jets application for direct laser etching which could also be used for selective thin film removal [29]. Usually direct laser etching with IR lasers is not available to fabricate microstructures because the traditional laser optical heads are constrained by the diffraction limit. Many people have already attempted applying the photonic jets for marking or surface patterning. However, most of them consider pico/femto-second or ultraviolet lasers [30-39].

The photonic jets interests for direct laser etching applications can be understood, because:

1. The photonic jets allow high concentration of light intensity with factor from 20 to more than 200 $[29,32,33]$. This factor can allow lower power laser, like nanosecond infrared lasers, to process materials with low absorbance.

2. The photonic jets have a full-width at half maximum (FWHM) or beam width that can be smaller than $\lambda$ and go beyond the diffraction limit [30, 33-35]. This allows nanosecond lasers give narrower heat-affected zone.

3. The photonic jets etching size can be predicted from preliminary simulation [32]. This privilege can allow any practitioner to arrange the photonic jets accordingly. 
For these reasons, it is possible to employ For these reasons, it is possible to employ nanoseconds-infrared lasers for micro-etching by applying them on dielectric microsphere so the photonic jets emerge and etch the material. By this way, it will reduce the investment cost, because the price of nanosecond lasers is significantly smaller than the one of pico or femto-second lasers. Moreover, it may reduce lasers overall operating cost, because the maintenance cost of infrared lasers - Nd:YAG laser for example - is smaller than to the one of ultravioletexcimer lasers.

In this paper a near-infrared laser is considered: a 28 nanosecond Nd:YAG laser with $1064 \mathrm{~nm}$ wavelength and an average power of 5W. Glass microspheres (mean diameters D of 35, 24, 6 and $4 \mu \mathrm{m}$ ), and two samples silicon wafers and glass plates are used.

\section{EXPERIMENTAL}

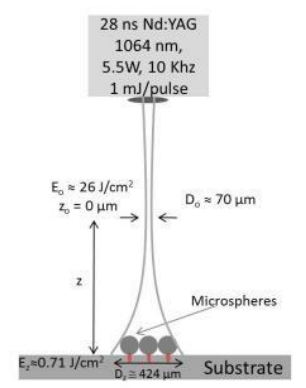

(a)

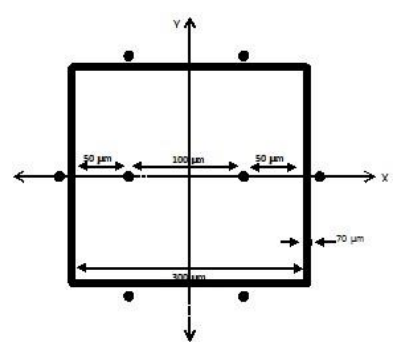

(b)
Figure 2. Experiment setup (a) schematic design and (b) localization cell.

The experimental setup deployed in this paper is presented by a schematic design in Fig.2(a). Microspheres are randomly sown on the sample. A defocusing of $z=22$ $\mathrm{mm}$ is achieved. At this position, the $\mathrm{Nd}$ :YAG laser cannot makeany mark on silicon since its fluence is below the laser-induced damage-threshold (LIDT) of silicon, i.e. 2 - 5 $\mathrm{J} / \mathrm{cm}^{2}$ [40-42]. However at this position the $\mathrm{Nd}$ :YAG laser beam width expands from $D_{\mathrm{o}} \cong 70 \mu \mathrm{m}$ to $D_{\mathrm{z}} \cong 425 \mu \mathrm{m}$ that allows many microspheres being illuminated at the same time. Localization cells (Fig. 2b) are also prepared to permit the correlation between microsphere positions and photonic jets micro-etching.

Four localization cells are prepared on each sample in order to experiment four different laser illumination schemes, i.e. etching using one, two, three and five pulses laser. The Nd:YAG laser is able to etch these four cells on silicon wafer placed at the focal point of the laser (Fig. 3a); with line width of $60 \mu \mathrm{m}$. However the same scheme cannot be applied on the glass plates, because of their low absorbance in near infrared; the LIDT of glass for nanosecond Nd:YAG laser is about $100 \mathrm{~J} / \mathrm{cm}^{2}$ [43]. These four cells have been drawn by scrubbing a black ink spread on the glass surface (Fig. 3b) using the Nd:YAG laser.

Microspheres are randomly sown on all cells. The sample is placed at the defocused position $z$. After the laser illumination all the marks correlated to a microsphere position are observed and measured.

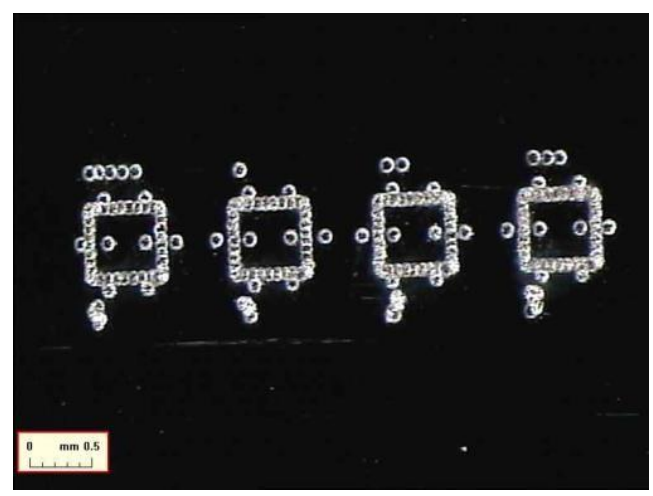

(a)

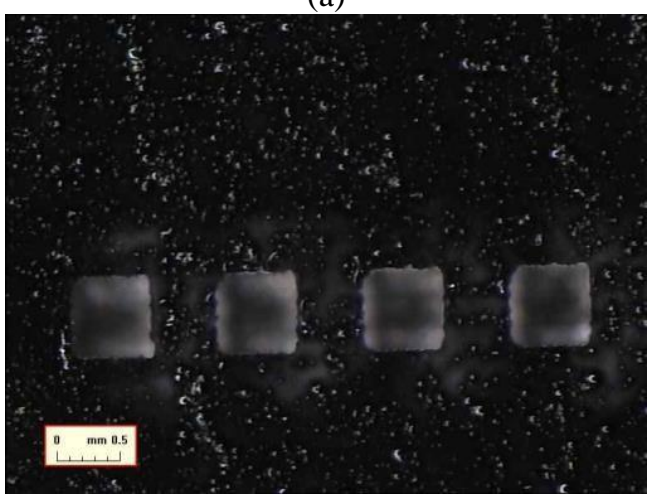

(b)

Figure 3. Four localization cells on (a) silicon wafer and (b) glass plate

\section{RESULTS}

Three photonic jets etching-shapes have been obtained in these experiments (Fig. 4): i.e. good and smooth etching, rough etching and circular-ring etching. The good and smooth etching-shapes are obtained on silicon wafer by the smallest glass microspheres ( $D_{\mathrm{s}}$ of 6 and $\left.4 \mu \mathrm{m}\right)$. The larger glass microspheres yield on silicon rough etching-shapes with sharp spikes or hillocks and rugged slopes. On glass plates, all marks have circular-ring shape; relatively smooth with glass micro-spheres and more rugged with $\mathrm{BaTiO}_{3}$ microspheres.

The smallest etching mark on silicon has a diameter of $0.6 \mu \mathrm{m}$ (Fig. 4a) laid in a cell with $D_{\mathrm{s}}=6 \mu \mathrm{m}$ glass microspheres after a three laser-pulses illumination. The mean etching mark diameter in this cell, i.e. $1.3 \pm 0.4 \mu \mathrm{m}$, is not the smallest mean etching mark diameter. The smallest mean diameter is $1.15 \pm 0.15 \mu \mathrm{m}$ yield in a cell with $D_{\mathrm{s}}=4$ 
$\mu \mathrm{m}$ glass microspheres after a two laser-pulses illumination. These features are equal or close enough to simulations results presented in Introduction. And somehow, no significant correlation is observed between the number of pulses and the micro-etching size (diameter and depth). It seems that a part of the evaporated material, ejected, after the first pulses, adheres to the microsphere and makes decrease the incident power of the following pulses.

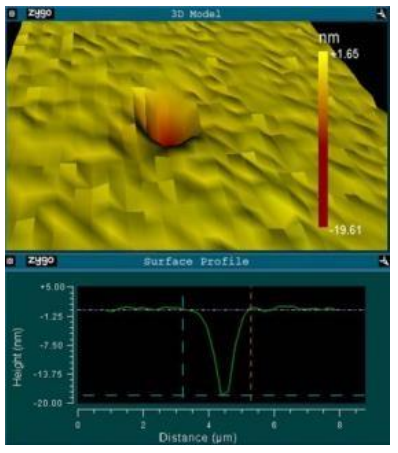

(a)

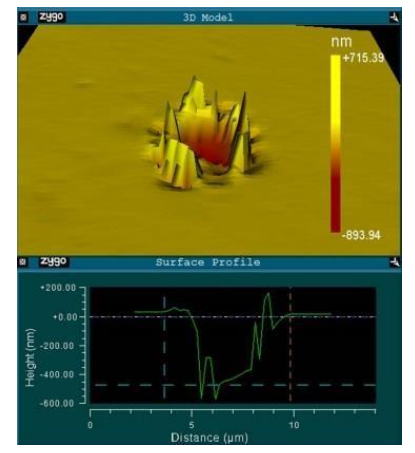

(b)

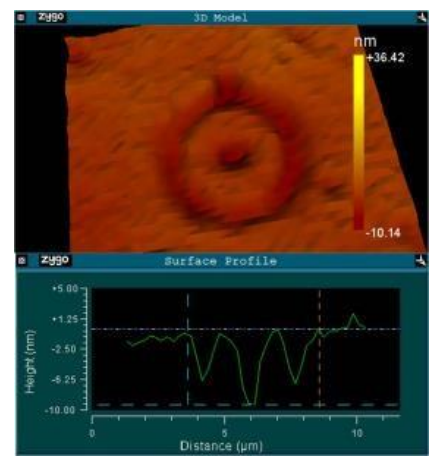

(c)

Figure 4. Three photonic jets etching-shapes, i.e. (a) a good and smooth etching-shape; yielded on silicon by a $6 \mu \mathrm{m}$ glass microsphere, (b) rough etching shape; yielded on silicon a by $24 \mu \mathrm{m}$ glass microsphere, and (c) circular-ring etching; yielded on glass by a $24 \mu \mathrm{m}$ glass microsphere.

The two smallest microspheres ( $D_{\mathrm{s}}$ of 6 and $4 \mu \mathrm{m}$ ) fail to etch the glass plate. Thus, the smallest mean central mark diameter $(1.6 \pm 1.15 \mu \mathrm{m})$ with the smallest mean ring diameter $(4.6 \pm 0.5 \mu \mathrm{m})$ are yielded by the $24 \mu \mathrm{m}$ glass microspheres. And, it turns out that the circular-ring etching shape on glass (Fig. 4c) has the same shape like the photonic jets simulation (Fig. 5). These simulations also show that the highest photonic jets fluence emerging from the $D_{\mathrm{s}}=6$ and $\mathrm{D}_{\mathrm{s}}=4 \mu \mathrm{m}$ glass microspheres, respectively, $41 \mathrm{~J} / \mathrm{cm}^{2}$ and $33 \mathrm{~J} / \mathrm{cm}^{2}$, are below the LIDT of glass.

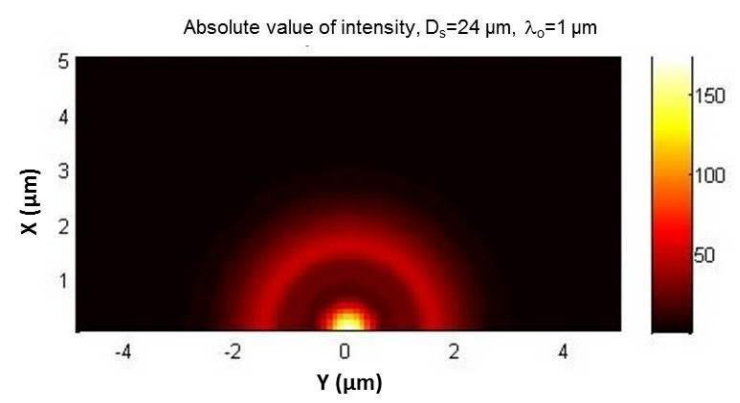

Figure 5. Intensity that emerges from a glass sphere $\left(n_{\mathrm{s}}=1.5 ; D_{\mathrm{s}}=24 \mu \mathrm{m}\right)$ in the output plan when illuminated by a unitary plane wave $\lambda_{\mathrm{o}}=1 \mu \mathrm{m}$ in free space.

\section{CONCLUSION}

Employing a 28 nanoseconds $1064 \mathrm{~nm}$ infrared Nd:YAG laser and glass microspheres, it has been demonstrated that photonic jets are able to etch silicon in micrometric size (1.3 $\pm 0.4 \mu \mathrm{m}), 50$ times smaller than direct laser etching without sphere. Also, photonic jets can enhance a nanosecond Nd:YAG laser fluence so it can etch glass plate. Therefore applying the photonic jets for surface micro-etching is a viable option.

\section{ACKNOWLEDGMENT}

This research is conducted in collaboration with Irépa Laser and some part of funding come from the overseas scholarships program of directorate general of high education of the government of Indonesia.

\section{REFERENCES}

[1] Z. G. Chen, A. Taflove, and V. Backman, IEEE Antennas and Propagation Society Symposium, vol. 1-4, pp. 1923, 2004

[2] Z. G. Chen, A. Taflove, and V. Backman, Optics Express, vol. 12, pp. 1214, 2004.

[3] V. Itagi and W. A. Challener, Journal of the Optical Society of America a - Optics Image Science and Vision, vol. 22, pp. 2847, 2005.

[4] S. Lecler, Y. Takakura, and P. Meyrueis, Optics Letters, vol. 30,pp. 2641, 2005.

[5] X. Li, Z. G. Chen, M. P. Siegel, A. Taflove, and V. Backman, "Analysis of nanoparticles using photonic Nano Jet," in Nanobiophotonics and Biomedical Applications II. vol. 5705, A. N. Cartwright and M. Osinski, Eds., ed 2005, pp. 14-22.

[6] X. Li, Z. Chen, A. Taflove, and V. Backman, Optics Express, vol. 13, pp. 526, 2005.

[7] A. Heifetz, K. Huang, A. V. Sahakian, X. Li, A. Taflove, and V. Backman, App. Phys. Lett., vol. 89, 2006.

[8] S. Lecler, S. Haacke, N. Lecong, O. Cregut, J. L. Rehspringer, Y. Takakura, et al., "Two-photon absorption enhancement using photonic jets" SPIE Photonics Europe, Strasbourg, France, 3-7 avril, 2006. 
[9] S. Lecler, S. Haacke, N. Le Cong, O. Cregut, J. L. Rehspringer, and C. Hirlimann, "Enhancement of two-photon excited fluorescence by sub-micron photonic jets," in Ultrafast Phenomena XV. vol. 88, P. Corkum, D. Jonas, R. J. D. Miller, and A. M. Weiner, Eds., ed, pp. 181-183, 2007.

[10] S. Lecler, S. Haacke, N. Lecong, O. Cregut, J. L. Rehspringer, and C. Hirlimann, Optics Express, vol. 15 ,pp. 4935, 2007.

[11] A. Devilez, B. Stout, N. Bonod, and E. Popov, Opt. Exp., vol. 16, pp. $14200,2008$.

[12] H. X. Ding, L. L. Dai, and C. C. Yan, Ch. Opt. Lett., vol. 8, pp. 706, 2010.

[13] D. McCloskey, Y. P. Rakovich, and J. F. Donegan, 12th International Conference on Transparent Optical Networks (ICTON), Munich, Germany, 2010.

[14] Y. E. Geints, E. K. Panina, A. A. Zemlyanov, and A. Electromagnetics, "Manipulating Photonic Nanojet Parameters of Micron-sized Dielectric Microspheres," in Piers 2011 Suzhou: Progress in Electromagnetics Research Symposium, ed, pp. 794-798, 2011.

[15] Y. E. Geints, A. A. Zemlyanov, and E. K. Panina, J. Opt. Soc. Am. BOptical Physics, vol. 28, pp. 1825, 2011.

[16] Y. E. Geints, A. A. Zemlyanov, and E. K. Panina, Quantum Electronics, vol. 41, pp. 520, 2011.

[17] D. Grojo, L. Charmasson, A. Pereira, M.Sentis, and P. Delaporte, Journal of Nanoscience and Nanotechnology, vol. 11, pp. 9129, 2011.

[18] M. S. Kim, T. Scharf, S. Muhlig, C. Rockstuhl, and H. P. Herzig, Opt. Exp., vol. 19, pp. 10206, 2011.

[19] M. S. Kim, T. Scharf, S. Muhlig, C. Rockstuhl, and H. P. Herzig, "Photonic Nanojet engineering: Focal point shaping with scattering phenomena of dielectric microspheres," in Conference on Integrated Optics - Devices, Materials, and Technologies XV, San Francisco, CA, 2011.

[20] J. J. Wang, D. McCloskey, and J. F. Donegan, "Optimization of parameters of photonic nanojet generated by dielectric microsphere for laser nanojet SNOM," pp. 83213Z-83213Z, 2011.

[21] Wenger, B. Stout, S. Monneret, et al., Opt. Lett., vol. 37, pp. 3531, 2012.

[22] Y. E. Geints, A. A. Zemlyanov, and E. K. Panina, J. Opt. Soc. Am. BOptical Physics, vol. 29, pp. 758, 2012.

[23] S. S. Stafeev and V. V. Kotlyar, Journal of Atomic, Molecular, and Optical Physics, vol. 3, 2012.

[24] Y. Takakura, H. Halaq, S. Lecler, S. Robert, and B. Sauviac, IEEE Photonics Technology Letters, vol. 24, pp. 1516, 2012.

[25] V. Yannopapas, Opt. Comm, vol. 285, pp. 2952, 2012.

[26] L. N. D. Kallepalli, D. Grojo, L. Charmasson, P. Delaporte, O. Uteza, A. Merlen, et al., J. Phys. D: Applied Physics, vol. 46, 2013.

[27] Y.-1. Ku, C.-f. Kuang, X. Hao, H.-f. Li, and X. Liu, Optoelectronics Letters, vol. 9, pp. 153, 2013.

[28] L. Han, Y. P. Han, J. J. Wang, G. Gouesbet, and G. Grehan, Opt. Lett., vol. 39, pp. 1585, 2014.

[29] N. Fukuda, K. Kunishio, and S. Nakayama, Journal of Laser Micro Nanoengineering, vol. 2, pp. 241, 2007.

[30] Y. F. Lu, L. Zhang, W. D. Song, Y. W. Zheng, and B. S. Luk'yanchuk, Journal of Experimental and Theoretical Physics Letters, vol. 72, pp. 457, 2000.

[31] A. Chimmalgi, C. P. Grigoropoulos, and K. Komvopoulos, J. App. Phys., vol. 97, pp. 12, 2005.

[32] H. J. Münzer, M. Mosbacher, M. Bertsch, J. Zimmermann, P. Leiderer, and J. Boneberg, Journal of Microscopy, vol. 202, pp. 129, 2001.

[33] W. Wu, A. Katsnelson, O. G. Memis, and H. Mohseni, Nanotechnology, vol. 18, 2007.

[34] S. M. Huang, M. H. Hong, B. S. Luk'yanchuk, Y. W. Zheng, W. D. Song, Y. F. Lu, et al., J. App. Phys., vol. 92, pp. 2495, 2002.
[35] S. Theppakuttai and S. Chen, App. Phys. Lett., vol. 83, pp. 758, 2003.

[36] A. Plech, V. Kotaidis, M. Lorenc, and J. Boneberg, Nat. Phys., vol. 2, pp. 44, 2006.

[37] A. Plech, P. Leiderer, and J. Boneberg, Laser \& Photonics Reviews, vol. 3, pp. 435, 2009.

[38] W. Guo, Z. B. Wang, L. Li, D. J. Whitehead, B. S. Luk'yanchuk, and Z. Liu, App. Phys. Lett., vol. 90, pp. 3, 2007.

[39] E. McLeod and C. B. Arnold, Nat. Nanotechnology, vol. 3, pp. 413, 2008.

[40] X. Wang, Z. H. Shen, J. Lu, and X. W. Ni, J. App. Phys., vol. 108, 2010.

[41] V. K. Arora and A. L. Dawar, App. Opt., vol. 35, pp. 7061, 1996.

[42] J. R. Meyer, M. R. Kruer, and F. J. Bartoli, J. App. Phys., vol. 51, pp. 5513, 1980.

[43] J.-Y. Natoli, L. Gallais, H. Akhouayri, and C. Amra, App. Opt., vol. 41, pp. 3156, 2002. 